\title{
ANALISIS PERBANDINGAN SISTEM CLOUD AZURE DAN GOOGLE CLOUD
}

\author{
Abdul Rahman Hakim \\ Magister Teknik Informatika, Universitas Sumatera Utara \\ Jl. Universitas No.9A Kampus USU, Medan, Sumatera Utara-Indonesia \\ hakim@gmail.com
}

\begin{abstract}
Abstrak - Penggunaan sistem operasi sebagai penghubung antara Media Perangkat Keras (Hardware) dengan Perangkat Lunak (Software) sebagai pengendali yang bertujuan untuk menghindari kesalahan-kesalahan dalam melakukan langkah-langkah pengoperasian suatu sistem. Kedua perangkat ini dapat duganakan sebagai penyedia layanan kepada pengguna (user), sehingga dapat memudahkan pengguna untuk mengoperasikan suatu sistem yang terdapat didalam Perangkat Keras dan Perangkat Lunak.
\end{abstract}

Keywords - Cloud Computing, Windows Azure Cloud, Google Cloud.

\section{PENDAHULUAN}

Pemilihan suatu madia penyimpanan dalam penggunaan Sistem Operasi saat ini sudah memiliki banyak pilihan, salah satunya adalah media Cloud. Cloud computing mungkin masih samar terdengar bagi orang awam. Tetapi keberadaan cloud computing di era digital kini sebenarnya telah terasa di tengah masyarakat dalam kehidupan sehari hari seperti penggunaan email dan juga media sosial.

Teknologi komputer berbasis sistem Cloud ini merupakan sebuah teknologi yang menjadikan internet sebagai pusat server untuk mengelola data dan juga aplikasi pengguna. Teknologi ini mengizinkan para pengguna untuk menjalankan program tanpa instalasi dan mengizinkan pengguna untuk mengakses data pribadi mereka melalui komputer dengan akses internet.

Dengan begitu pesatnya perkembangan teknologi dan globalisasi, banyak sekali penyedia layanan Cloud Computing yang menawarkan pelayanan jasa tersebut. Seperti halnya Dropbox, iCloud, Azure, Google, dan masih banyak lagi. Penelitian ini membahas tentang membandingkan penyedia layanan Cloud Computing Azure dan Google Cloud. Dimulai dari teknologi dasar, aplikasi yang ditawarkan, dan teknologi masa depan yang mereka kembangkan.

\section{RUMUSAN MASALAH}

Berdasarkan pendahuluan diatas, maka dapat dirumuskan permasalahannya sebagai berikut :

1. Apa saja teknologi dasar yang ada pada Windows Azure dan Google Cloud?

2. Bagaimana perkembangan Windows Azure dan Google Cloud?

3. Apa saja aplikasi yang dikeluarkan oleh Windows Azure dan Google Cloud?

4. Bagaimana perbandingan kualitas antara Windows Azure dan Google Cloud?

5. Bagaimana ekspektasi teknologi masa depan Windows Azure dan Google Cloud?

\section{METODOLOGI PENELITIAN}

Cloud Computing atau komputasi awan adalah komputasi berbasis internet dimana semua layanan dapat digunakan atau di akses melalui internet. Secara teknis gabungan dari banyak server untuk menyediakan sumber daya agar dapat di manfaatkan bersama. Sumber daya bisa berupa aplikasi, storage, data dan lain lain. Sebenarnya sebagian teknologi ini sudah akrab dengan kita seperti layanan email, yahoo, plasa, google, hotmail, skydrive, google doc dan office Web app.

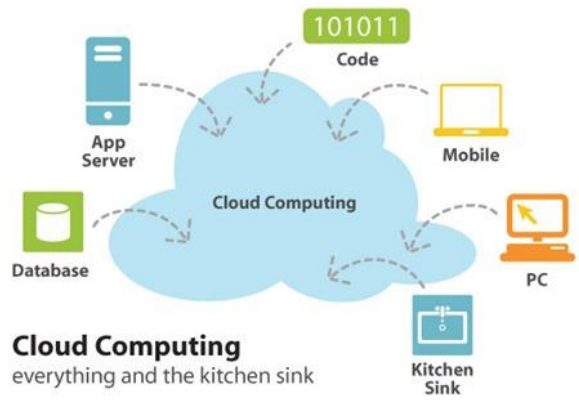

Gbr.1 Gambaran Cloud Computing

Virtualisasi adalah tahap awal menuju Cloud Computing. Virtualisasi "melepaskan" ikatan antara Hardware dan fungsi kendali manajemennya, sehingga menjadi virtual machine. Sejauh ini kita sudah berhasil mem-virtualisasi-kan server, storage, dan aplikasi sehingga menjadi resource pool, satu pusat sumberdaya komputasi. Resource Pooling ini lah yang menjadi karakteristik Cloud.

\section{A. Teknologi Dasar Windows Azure}

Replikasi a Dalam perkembangan cloud computing yang cukup pesat di Indonesia saa tini, salah satu nama yang mencuat adalah Windows Azure. Teknologi bentukan Microsoft ini adalah sebuah bentuk implementasi Platform as a Service (PaaS) dari sebuah 
cloud computing. Teknologi ini memungkinkan kita untuk membangun sebuah aplikasi melalui cloud, baik berupa teknologi web application, cloud service, maupun aplikasi-aplikasi yang berjalan di atas virtual machine.

Salah satu yang menjadi keunggulan Windows Azure adalah kemampuan untuk menjalankan aplikasi dari berbagai jenis teknologi dan platform, diantaranya adalah .NET (sebagai teknologidari Microsoft), JAVA, dan juga PHP.

Berdasarkan sejarahnya, teknologi ini pertama kali diperkenalkan pada tahun 2008 dan terus dikembangkan sehingga menjadi komersial secara umum pada tanggal 1 Februari 2010.

Terdapat tiga buah komponen dari teknologi Windows Azure, diantaranya adalah :

1. Compute : Merupakan bagian dari teknologi Windows Azure yang berguna dalam proses komputasi, baik secara foreground maupun background job (berjalan di belakang layar). Compute tools dari Windows Azure diantaranya adalah web role, worker role, dan virtual role.

2. Storage : Merupakan bagian dari teknologi Windows Azure yang berguna dalam proses penyimpanan data. Terdapat duajenis storage dalam Windows Azure, yang pertama adalah Azure Storage yang berguna untuk penyimpanan data yang berbentuk table, cloud, dan blob. Sementar aitu, bentuk storage lainnya adalah SQL Azure yang merupakan versi SQL Server yang berjalan di cloud.

3. Fabric : Merupakan bagian yang berguna sebagai "otak" dari teknologi ini. Proses ini diaturoleh Windows Azure Fabric Controller yang berguna dalam proses scheduling, resource allocation, dan management.

Windows Azure bersandar pada teknologi REST (Representational State Transfer) sehingga proses komunikasi antar aplikasi dapat dilakukan dengan menggunakan protokol HTTP. Abstraksi dari konsep Windows Azure dapat dilihat pada gambar di bawah ini :

\section{Windows'Azure}

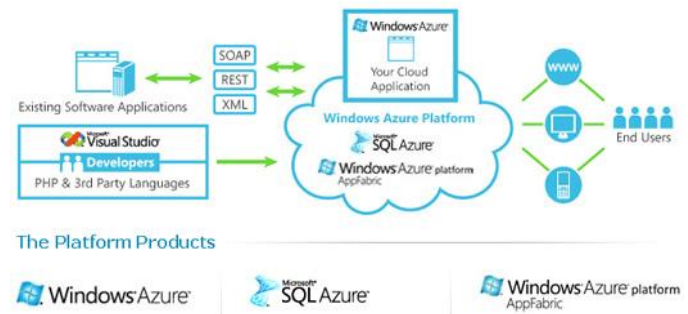

Gbr.2 Skema Windows Azure

\section{B. Teknologi Dasar Google Cloud}

Komputasi awan (cloud computing) menurut definisi Google adalah pusat data yang ada di luar komputer aplikasi klien. Tujuan utama dari Google berkontribusi dalam komputasi awan adalah untuk memanfaatkan sumberdaya komputer yang dimilikinya dalam jumlah yang sangat besar yang berjumlah jutaan komputer dan tersebar di seluruh dunia serta untuk mempercepat operasi-operasi yang dilakukan oleh aplikasi-aplikasi Web saat ini. Dalam hal ini, komputasi awan yang dikembangkan oleh Google pada dasarnya berada di seputar jaringan komputer raksasa yang bekerja untuk aplikasi-aplikasi utamanya seperti Google Search dan Google Mail (GMail).

Meski demikian, tidak sembarang aplikasi dapat berjalan di komputer-komputer milik Google yang membentuk jaringan komputasi awan itu. Agar dapat berjalan dengan baik, aplikasi-aplikasi harus dikembangkan menggunakan 'aturan-aturan' yang ditetapkan oleh Google. Aplikasi-aplikasi seperti itu dinamakan sebagai Google App Engine (GAE), dimana saat ini aplikasi-aplikasi jenis ini bisa ditulis dengan cara yang relatif mudah oleh para pemrogram komputer yang memahami bahasa pemrograman Java dan Phyton.

\section{IMPLEMENTASI}

\section{A. Fitur Pada Windows Azure}

Web Sites

Web sites di windows azure ini seperti hosting dan domain seperti di tempat hosting-hosting lain, namun perbedaannya adalah web yang kita buat berada di dalam windows azure.

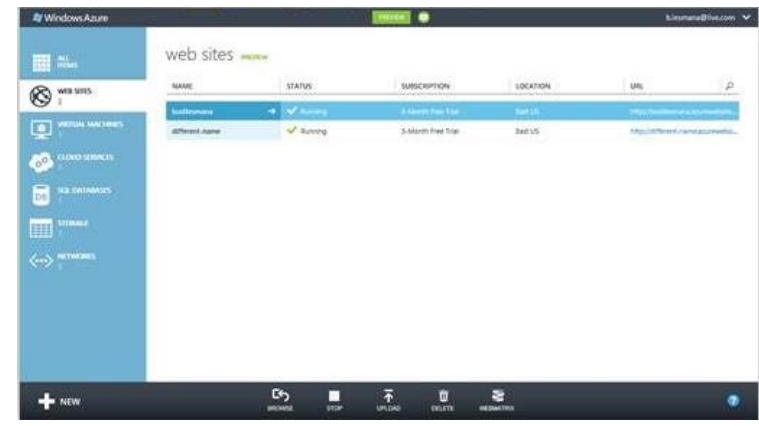

Gbr.3 Web Site di Windows Azure

\section{Virtual Machines}

Virtual Machines di windows azure tidak jauh berbeda dengan VM lain seperti Vmware, VirtualBox dll. Perbedaannya di windows azure, kita bisa memilih OS yang telah di sediakan, Seperti Windows Server 2008 R2, Server 2012 RC, SQL Server 2012, di sini Microsoft juga mengikut sertakan OS OpenSource Seperti Ubuntu Server, OpenSuse, CentOS, dan lain lain. 


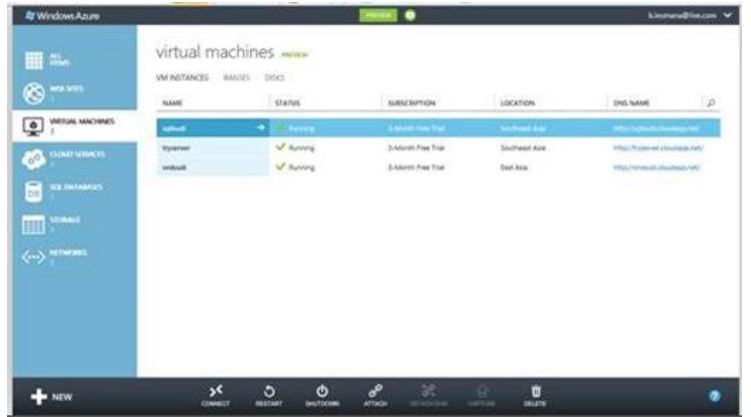

Gbr.4 Virtual Machines Windows Azure

Cloud Services

Adalah layanan PaaS. Jika ingin membuat situs web atau aplikasi web, user dapat secara langsung mengakses dari Windows Azure website seperti di bawah ini.

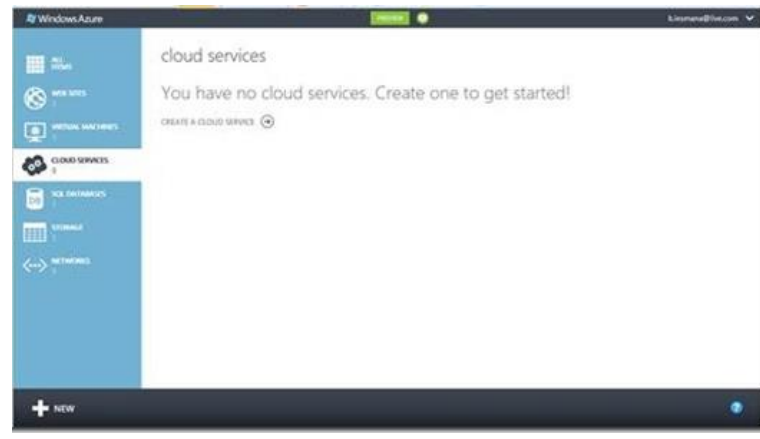

Gbr.5 Clouds Service

\section{SQL Database}

SQL database atau biasa yang di sebut SQL Azure, di sini fungsinya tidak jauh berbeda dengan SQL Server yang biasa, namun ini teknologi cloud, kita bisa menulis query-query di dalam Cloud dan membuat database secara online, tanpa instalasi software.

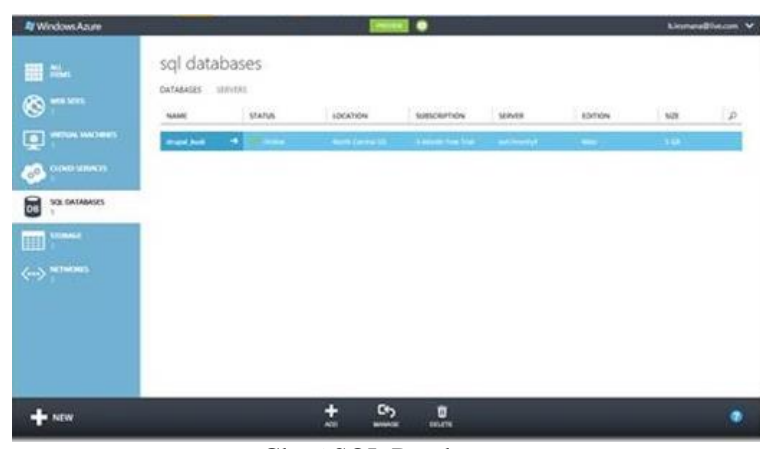

Gbr.6 SQL Database

Storage

Storage di windows azure ini, adalah Storage yang terbentuk pada saat kita membuat Virtual Machine di windows azure.

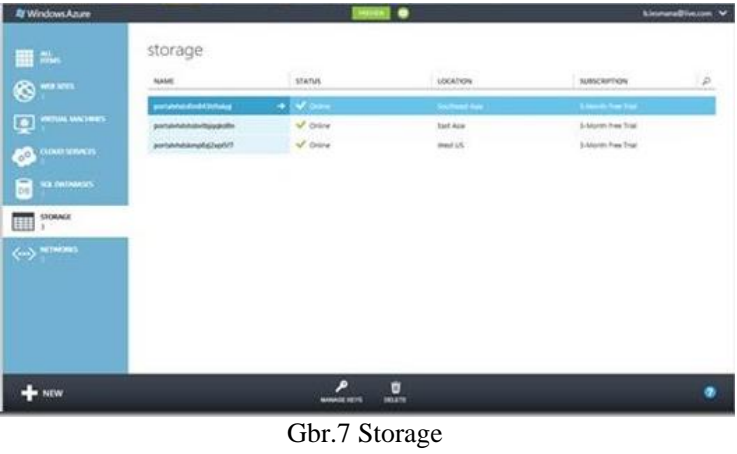

Virtual Networks

Virtual networks disini berguna untuk menaikkan komposisi kerja dari layanan cloud dengan memperbolehkan satu atau lebih dari layanan cloud tersebut untuk ditambahkan ke virtual network.

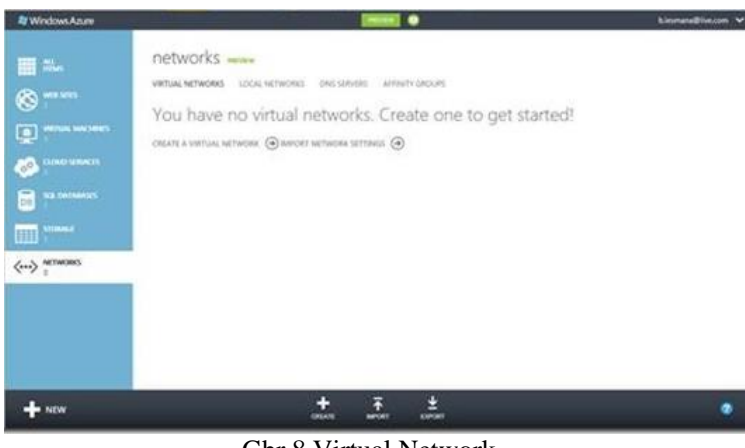

B. Fitur Pada Google Cloud

Google App Engine

Google App Engine juga merupakan salah satu Platform as a Service (PaaS). Google App Engine memungkinkan Anda menjalankan aplikasi web pada infrastruktur Google. Dengan App Engine, tidak memerlukan server. Anda hanya mengunggah aplikasi Anda. Dan aplikasi tersebut sudah dapat bisa digunakan oleh pengguna Anda.

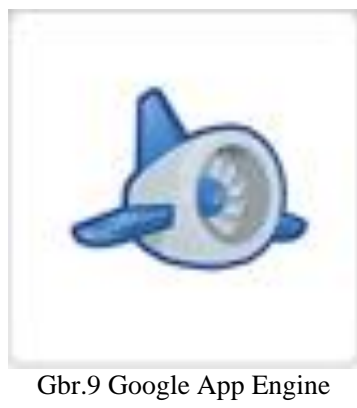

Google Compute Engine

Google Compute Engine menawarkan kemampuan mesin komputasi virtual dalam sistem cloud yang fleksibel dan scalable. Dengan Google Compute Engine, Anda dapat memecahkan proses skala besar dan masalah analitik pada infrastruktur komputasi, storage, dan jaringan Google. 


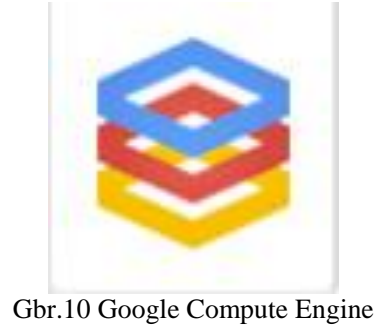

Google Cloud Storage

Merupakan layanan baru untuk para pengembang menyimpan dan mengakses data di Google Cloud. Fitur ini melayani para pengembang untuk mengakses langsung Google's scalable storage dan infrastuktur jaringan yang sama baiknya dengan autentifikasi dan mekanisme data sharing yang kuat.

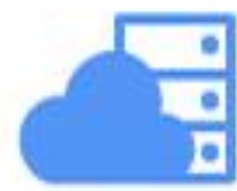

Gbr.11 Google Compute Engine

Google BigQuery

Google BigQuery memungkinkan Anda untuk menjalankan SQL seperti query pada dataset yang sangat besar, dengan memiliki ratusan baris. Hal ini bisa data Anda sendiri atau data orang lain yang dibagikan kepada Anda. Untuk skenario database relational yang lebih tradisional, Anda mungkin perlu mempertimbangkan menggunakan Google Cloud SQL sebagai gantinya. Anda dapat menggunakan BigQuery melalui web UI yang disebut BigQuery browser tool, BigQuery command-line tool, atau dengan memanggil REST API menggunakan library dari berbagai klien dalam berbagai bahasa, seperti Java, Python, dan lain lain.

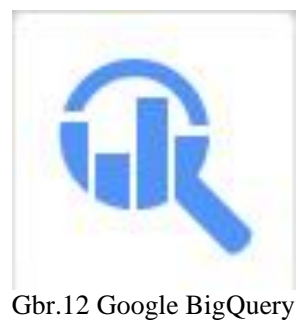

Google Cloud SQL

Merupakan database MySQL yang ada pada Google Cloud. Fitur ini memiliki semua kemampuan dan fungsi dari MySQL, dengan beberapa fitur tambahan. Google Cloud SQL mudah digunakan, tidak memerlukan instalasi perangkat lunak atau pemeliharaan dan sangat ideal untuk kecil hingga menengah aplikasi.

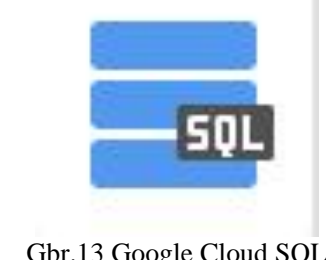

\section{KESIMPULAN}

Dari penelitian yang telah dilakukan, maka dapat disimpulkan bahwa teknologi cloud computing adalah suatu penemuan yang efektif untuk digunakan di masa depan. Google Cloud dan Microsoft Azure adalah salah satu dari banyak perusahaan yang mengembangkan cloud computing, dan kedua perusahaan ini memiliki kelebihan dan kekurangannya masing-masing yang tidak bisa untuk dibandingkan secara umum.

\section{REFERENSI}

[1] Pusat Teknologi, 2014, Pengertian, Manfaat, Cara Kerja dan Contoh Clud Computing, http://pusatteknologi.com. 22 Oktober 2015, 10.00 WIB

[2] Hill Z, Li J, Mao M, Ruiz-Alvarez A, \& Humphrey M, Early Observations on the Performance of Windows Azure, Department of Computer Science, University of Virginia, Charlottesville, VA 22904.

[3] Sofana, Iwan., Cloud Computing Teori dan Praktik (OpenNebula, Vmware dan Amazon AWS), Bandung: Informatika, 2012.

[4] Purbo, Onno W., Membuat sendiri Cloud Computing server menggunakan open source, Yogyakarta: Penerbit ANDI, 2012.

[5] HiTech, 2011, Windows Azure-The Cloud Computing Platform, www.tcs.com, 28 Oktober 2015, 17.00 WIB

[6] CHAPPELL, D., 2010, INTRODUCING THE WINDOWS AZURE PLATFORM, Chappell \& Associates. 